\title{
ADOPTION OF PRECISION AGRICULTURE TO REDUCE INPUTS, ENHANCE SUSTAINABILTIY AND INCREASE FOOD PRODUCTION: A STUDY OF SOUTHERN ALBERTA, CANADA
}

\author{
LORRAINE A. NICOL \& CHRISTOPHER J. NICOL \\ University of Lethbridge, Canada
}

\begin{abstract}
Precision agriculture (PA) identifies variability in fields. This allows greater accuracy in targeting the correct amount of inputs, at the correct time, and in the correct location compared to conventional agricultural methods. As such, precision agriculture has significant potential to reduce agricultural inputs, enhance agricultural sustainability, and increase production in order to meet the growing worldwide demand for food. This study focuses on southern Alberta, the largest, most fertile and productive agricultural region in Canada. Given the high concentration of agriculture in this region, the potential benefits of precision agriculture could be significant. A greater understanding of the adoption of precision agriculture is therefore warranted. Based on a survey of farmers, the study finds the region is actively advancing PA technologies and the findings indicate PA technologies tend to be spread across all land and crop types; the technologies are applied to both dryland and irrigated farms and across cereals, oilseeds and speciality crops. Farmers are highly satisfied with precision agriculture and intend to continue adoption of precision agriculture technologies. Further, some non-adopters intend to become adopters. If there are limits to adoption it is because some farms are too small to warrant the adoption of precision agriculture and the attendant high investment costs.

Keywords: agriculture technologies, precision agriculture, sustainability, food production, Alberta.
\end{abstract}

\section{INTRODUCTION}

Precision agriculture is a concept introduced in the mid 1980's. It involves knowledge-based technical management systems to optimize application of fertilizer, chemicals, seeds and irrigation water to reduce input costs, enhance crop yield and simultaneously reduce harmful environmental impacts associated with agriculture production [1].

Until the advent of PA, inputs were applied in a uniform rate across an entire field. Such a practice overlooked field variability [2]). PA technologies allow fields to be deconstructed into smaller, more precise sections, based on variability. Based on this variability, allocations of inputs can be more precisely determined and those applied under earlier agricultural practices. Ultimately PA involves the correct amount of inputs, at the correct time, in the correct location in the field, hence the term "precision agriculture".

PA has been deemed one of the top ten revolutions in agriculture [3]. PA has the potential to reduce farm crop inputs, reduce costs and increase farm profits. In addition, collateral damage to the environment can be mitigated if, for example, less nitrogen and phosphorus fertilizer is used, hence less run-off occurs on the landscape; if more water is left in the river rather than being applied to irrigated fields; and if there is less ground water contamination. Precision agriculture has therefore become fundamental to sustainable agriculture.

Beyond the economic and environmental benefits of precision agriculture is the prospect of increased world-wide food production hinging on the potential of increased crop yield through PA. According to the United Nations, global population is forecast to grow from 7.3 billion in 2016 to 9.7 billion in 2050 . Food demand is expected to increase anywhere between $59 \%$ to $98 \%$ by that time, an increased demand is attributed to this population growth as well 
as greater demand for protein and meat as rising incomes in developing countries translate into dietary changes [4]. Since the 1990's in the United States for example, when many of the new PA techniques were starting to be adopted, the annual rate of growth of total factor productivity in agriculture (total output divided by total input) accelerated from $1.49 \%$ to $1.91 \%$, much of this increase coming from less wasteful input use [5].

This study explores the current and future potential of achieving these input reduction, environmental sustainability, and productivity outcomes by studying the adoption of PA in southern Alberta.

\section{IMPLEMENTING PRECISION AGRICULTURE}

PA involves numerous technologies which can be adopted in piecemeal or in bundles [6]. PA also requires sophisticated knowledge with respect to data collection, data management, interpretation and decision making [2]. Cambouris et al. [7] identify three steps to the precision agriculture process. The first is identifying where, when, and how much variability is present within the field. Second is analysing the within-field variability to best determine how to manage it. Third is managing this within-field variability within respect to field inputs.

The technologies used to assess the spatial and temporal variability of fields includes global position systems (GPS), geographic information systems (GIS), yield monitors and remote proximal sensors (for example, satellite images). Technologies used to manage the variability include automatic guidance systems and variable rate application technologies for farm machinery [7].

Given the potential benefits of PA enumerated in the section above, gaging rates of adoption, and identifying the factors influencing adoption, are of considerable interest. But a myriad of factors influences farm decisions. Further, PA itself is complex. Nonetheless, various studies have explored adoption rates in the United States and Europe. One study found larger producers were more likely to adopt a higher number of precision agriculture technologies. The same study found irrigated producers were more likely to adopt technologies than those solely using dryland practices [8]. And farmers with more in-field variability adopted a larger number of PA technologies compared to those with less [9]. PA has been found to be positively correlated with the educational level of the producer and negatively correlated with the age of the operator. Computer literacy was also found to be a factor relating to adoption [10].

Studies of non-adopters found factors dissuading adoption include the high time required to collect and analyse data, lack of technical knowledge, skills and competences to manage PA tools, problems with incompatibility between different machinery and hardware devices, and the high cost of the technology [11], [12].

Few studies have explored adoption of PA in Canada. Aubert et al. [13] focussed on Quebec farm operators and found the perceived ease of use and perceived usefulness have a significant effect on PA adoption. Also, compatibility with existing equipment, routines and operations; quality of support, farmers' knowledge of PA technologies was all found to be significant factors affecting perceived usefulness [13]. A study of PA adoption in western Canada was conducted in 2017 [14]. The study found 84\% of farmers were using PA technologies. Over three quarters of the farms use GPS guidance, have combine yield monitoring capability, use GPS auto-steer equipment guidance and use automatic sectional control on equipment [14]. Characteristics of adopters were farmers with relatively large acreage, in the 35 to 54 age range, and who had high farm revenue. The top five barriers to adoption were cost, internet speeds and/or cellular data coverage, lack of knowledgeable people, continuously evolving technology and older farm equipment which is not compatible [14]. 


\section{STUDY AREA, OBJECTIVES AND METHODOLOGY}

Alberta is a western Canadian province with a population of approximately four million. The province's location within Canada is depicted in Fig. 1 below. The northern most part of the province is heavily forested and is known for its oil extraction industry. The southern portion of the province is largely agriculture-based prairie grassland, the area which is the focus of this study. Southern Alberta is depicted in Fig. 2 below.

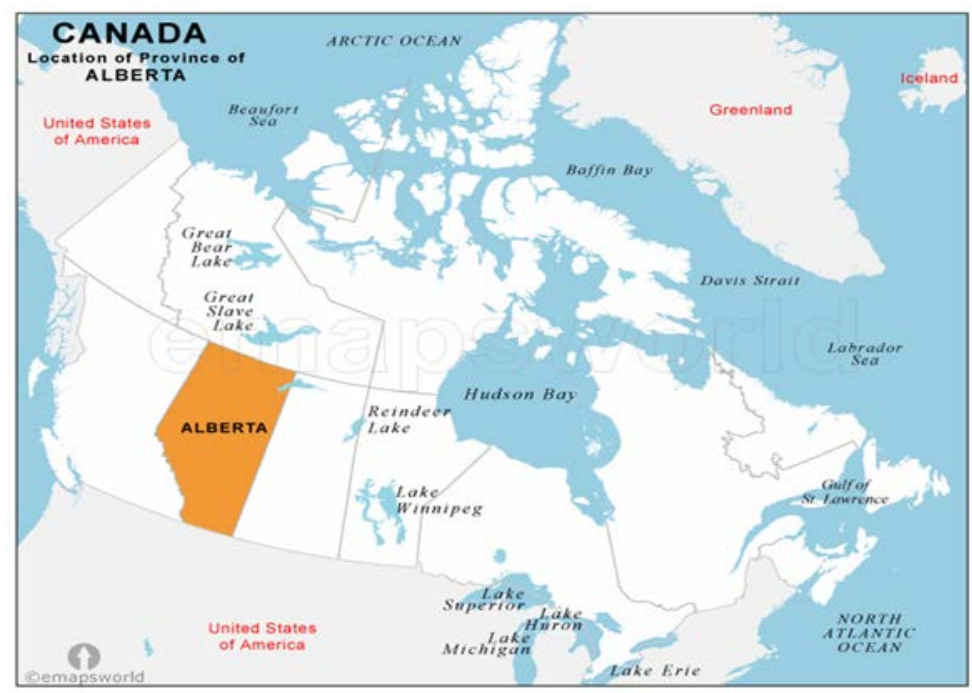

Figure 1: Alberta in Canada. (Source: http://www.simergphotos.com.)

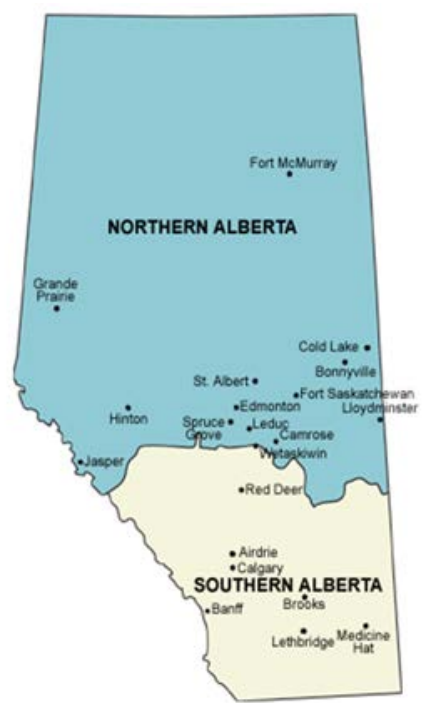

Figure 2: Southern Alberta. (Source: http://www.webcreationsbyjumpy.com/canada/ canadian_graphics/maps/maps_provinces/.) 
Southern Alberta is the largest, most fertile and productive agricultural region in Canada [15]. It consists of approximately 20,000 farms [16]. It has the largest irrigation system in Canada, representing $65 \%$ of all irrigated area in the country [17]. There are 13 irrigation districts as well as a number of private irrigation systems. Almost a third of jobs in the region are tied to irrigation [18].

Conventional crops grown in the region include spring and durum wheat, barley, canola, and forage crops. But under irrigation, more than 60 crop varieties are grown, including 28 speciality crops [19]. Some of these speciality crops include potatoes, beans, corn and sugar beets. The locally grown crops provide the basis for a significant processing industry. In addition, forage and silage produced under irrigation are used to support the confined feeding industry, making the region Canada's leader in cattle feeding and processing. Sixty per cent of feeder cattle in the region are associated with irrigated farms [20].

Southern Alberta is recognized for its entrepreneurial and progressive farm culture where new speciality crops, equipment and advances and precision agriculture and land management practices have emerged where the business of agriculture is shifting from food producers to agri-business [15, p. 1]. Given the agricultural importance of the region and its progressive culture, southern Alberta provides an ideal location for the study of the adoption of PA.

This study explored the PA adoption of crop producers in southern Alberta. The objectives of the study were to determine:

a) the extent to which PA technologies are being adopted, the type of PA technologies adopted; satisfaction with the technologies; what type of land and crops PA is primarily applied to; any future additional adoption intentions; farm and personal characteristics of adopters

b) the extent of non-adoption of PA technologies; the reasons for non-adoption; any future adoption intentions of non-adopters; farm and personal characteristics of non-adopters

Data collection was based on a survey questionnaire developed and posted on the SurveyMonkey software platform. The survey questions drew on previous published studies, tailored to local conditions and the study's objectives. Participants were recruited through the farm organization "Farming Smarter", which has extensive contact with farmers in the study region. It is a non-profit organization whose primary focus is on research that helps southern Alberta crop producers make knowledgeable choices around inputs, technology and management practices for their operation (see http://www.farmingsmarter.com/ for more detail of the organization).

Participants were recruited through Farming Smarter's network of connections to the farming community via the organization's website, Facebook and twitter postings, and their bi-annual magazine. As such, an invitation to participate in the study was posted on the home page of the organization's website, Facebook and twitter posts. The postings included a tab that directed the participant to the on-line survey questionnaire. The magazine included notification of the survey and was distributed via hard copy to 10,000 farm operators. The magazine was also posted on the organization's website. If magazine readers wanted to participate in the study, they were asked to go to the organization's website where they will find the link to the survey. Ethics approval to conduct the study was obtained from the University of Lethbridge on January 11, 2017. The survey was available from March 14, 2017 to April. 18, 2017.

Eighty-eight producers participated in the survey. Data were summarized on a questionby-question basis. Cross tabulations using SPSS were conducted to determine differences in adoption and non-adoption across location, personal and farm characteristics. The data analysis was alert to the emergence of common findings to ascertain if there are common 
characteristics amongst non-adopters as well as adopters. For non-adopters, the reasons why they have not adopted were useful in determining, if possible, what measures can be taken to assist with adoption.

The number of survey respondents was not sufficient to allow the results to be extrapolated to the entire southern Alberta farm population. However, the results do provide an indication of what may be occurring with precision agriculture in southern Alberta.

\section{RESULTS}

\subsection{Adopters}

The study found the majority of farmers in the region have adopted some form of PA. Eightysix percent have implemented one or more "basic" PA technologies (auto-steer technology, yield mapping, variable rate fertilizing, variable rate irrigation, GPS soil sampling and/or developing management zones). Sixty-three percent have implemented one or more "soil mapping" techniques (use of terrain mapping, electric conductivity mapping, satellite imagery and/or unmanned aerial vehicle mapping). Seventy-one percent have implemented one or more "data management" techniques (studying or analyzing yield data, using PA data management software or services, using PA technology for records and analysis and/or using PA for on-farm research). These results are depicted in Fig. 3 below.

When asked the reasons for adopting PA, more than half have a high rating to increased yield (58\%) and improved crop quality (53\%) but other major reasons related to reduced time $(55 \%)$ and reduced work load (53\%). Of lesser, but still important, reasons related to reduced inputs including pesticides $(41 \%)$, herbicides $(39 \%)$ and water $(19 \%)$. As relates to the environment in general, $41 \%$ indicated protection of the environment as a high reason for adoption. (Note - for a "high rating", on a scale of 0 to 5, a rating of 4 or 5 was deemed high.)

In the future (specified as the next five years), most adopters plan to continue PA implementation. Eighty-five\% indicated they would increase one or more PA techniques, especially data management (61\%) and soil mapping (30\%). Significantly less, only nine $\%$, plan to adopt basic PA technologies but this may be attributed to the fact $86 \%$ of adopters have already implemented basic PA technologies.

Across PA adopters, almost all are either highly or moderately satisfied with PA technologies, in total $94 \%$ as depicted in Fig. 4 below. Only $6 \%$ were dissatisfied.

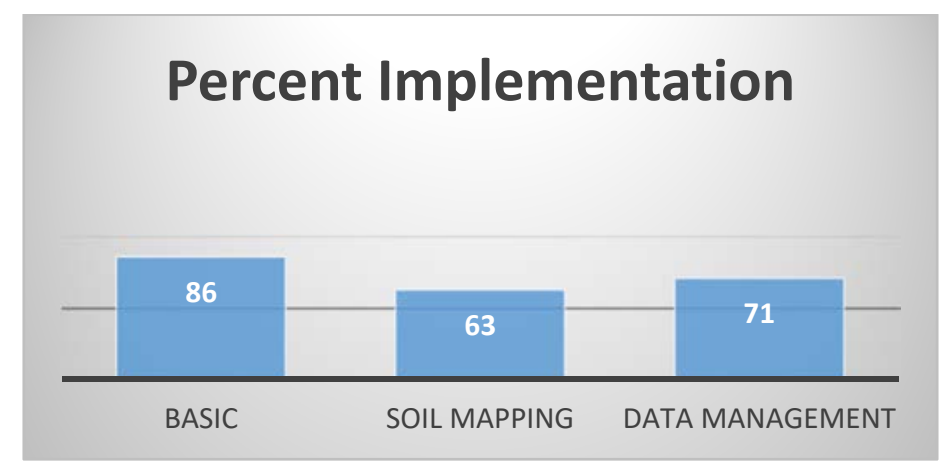

Figure 3: PA adoption. 


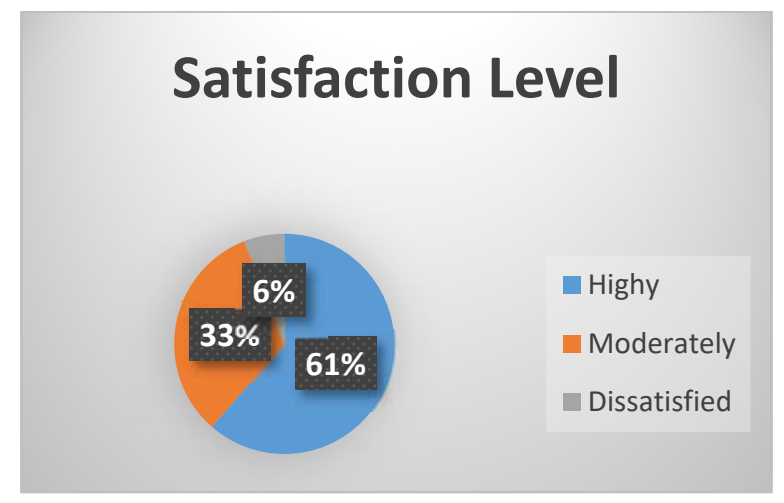

Figure 4: Satisfaction level.

As relates to the farm and personal characteristic adopters, the profile of adopters includes: use of PA on dryland more than on irrigated land; applying PA across all crop types; the majority not using consultants; having mid-size farms; being predominantly college and university educated; and being at least 35 years of age. More specifically the data indicate:

- Dryland versus irrigated land application: more PA technology was devoted to dryland compared to irrigated land $-58 \%$ devote PA technology exclusively to dryland, $38 \%$ to irrigated land and $6 \%$ to a combination of dryland and irrigated land.

- Crop type: PA application is almost evenly split between crop types: cereals - 33\%, oilseeds $-32 \%$ and speciality crops $-25 \%$. Only $10 \%$ devote PA to forages

- Use of consultants: A greater number of adopters do not use consultants (54\%) than those who use them $(46 \%)$.

- Farm size: the greatest proportion of adopters have mid-range farm sizes - the greatest percentage, $40 \%$, have farm size in the 2,000 to 5,000-acre range, another $28 \%$ have farm size of 500 to 1,999 acres with $20 \%$ having very large farms of greater than 5,000 acres and with $12 \%$ with very small farms of less than 500 acres.

- Education level: adopters are predominantly college educated (44\%) and university educated (36\%) with $15 \%$ having a high school diploma and $5 \%$ having a graduate degree.

- Farmer age: adopters were predominantly 35 years to 55 years of age $(43 \%)$ and over $55(36 \%)$ with just $21 \%$ being younger than 35 years of age.

\subsection{Non-adopters}

As noted in the previous section, there are high adoption rates of "basic" PA technologies. Thus, only $14 \%$ of survey participants were non- adopters of basic technologies. Twentynine percent had not adopted data management technologies and $37 \%$ had not adopted soil mapping technologies.

When asked from a list of reasons what are the main deterrents to adoption, the dominant reasons across the three categories of technologies was high investment costs (between 57\% and $67 \%$ specified this reason) followed by "my operation is too small" (between $37 \%$ and 
$67 \%$ ) and high time requirements (between 33\% and 38\%). (Note - participants could identify more than one reason.) These reasons are depicted in Fig. 5.

Nonetheless, approximately one-third to one-half of respondents indicated they plan on adopting some form of PA in the next five years, from to soil mapping (47\%), to data management (44\%), to basic technologies (32\%) as depicted in Fig. 6.

For non-adopters, the main motivation for adopting PA in the future differed across the types of PA technologies. For basic technologies, the main motivators were to reduce work ( $75 \%$ rated this reason as high) and reduced time (75\% also rated this reason as high). For soil mapping technology, the main motivator was to increase crop yield (71\% rates this reason as high).

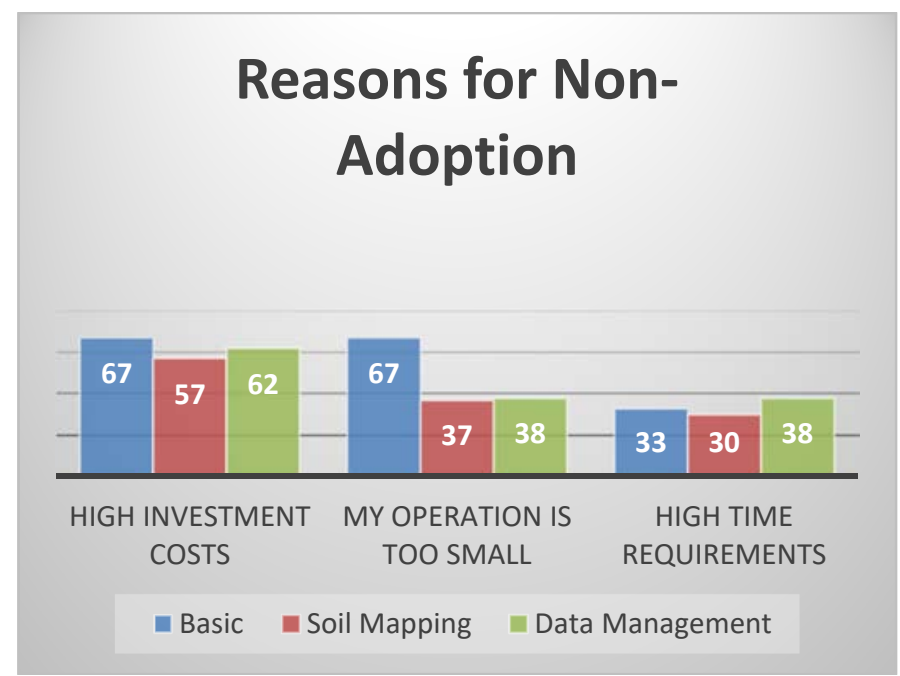

Figure 5: Reasons for non-adoption.

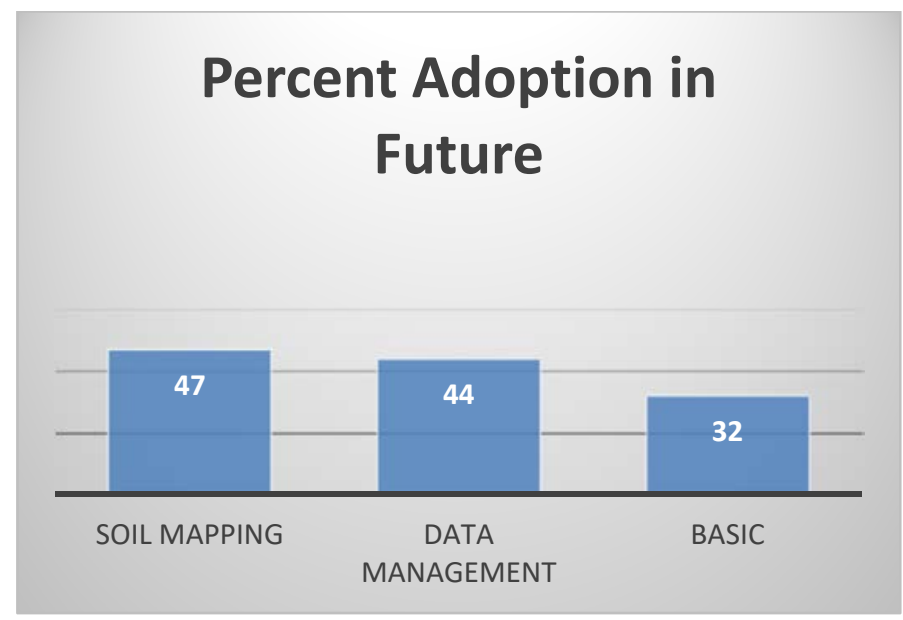

Figure 6: Future adoption. 
For data management technology, the main motivator was also increase crop yield ( $86 \%$ rates this reason as high).

Personal and farm characteristics of non-adopters were that they have relatively small farms, rare primarily college and university educated and are over 35 years of age. More specifically:

- Farm size: the greatest proportion of non-adopters have relatively small farm sizes $-60 \%$ have farm size of less than 2,000 acres: 55 acres $27 \%$ and 500 to 1,999 acres $33 \%$. Forty percent have 2,000 acres or more: 2,000 to $5,00027 \%$ and greater than 5,000 acres $13 \%$.

- Education level: non-adopters are predominantly college educated (40\%) and university educated (33\%) with $20 \%$ having a high school diploma and $7 \%$ having a graduate degree

- Farmer age: non-adopters are predominantly 35 years to 55 years of age (47\%) and over 55 at $37 \%$, with just $6 \%$ being younger than 35 years of age.

\section{OBSERVATIONS AND CONCLUSIONS}

Findings from this study underscore the progressive nature of farming in this region. The study found high rates of adoption of basic PA technologies with somewhat lower, but still high, adoption of more advanced technologies of soil mapping and data management. Adopters expressed high levels of satisfaction with PA technologies and the vast majority of them intend on continuing to adopt in the future.

For non-adopters, high investment costs are the main deterrent to adopting. This is consistent with the findings of other studies. Also, amongst non-adopters in this study, some farm operations are too small to warrant the investment of PA technologies. Indeed, when comparing the characteristics of adopters and non-adopters, the only characteristic that separates the groups is their farms size - adopters have relatively large farms and nonadopters have relatively small. In this study there were no noticeable differences between adopters and non-adopters as relates to education levels and age ranges.

The cost of new technologies tends to decrease over time. Therefore, non-adopters, who find the current cost of the technology prohibitive, may over time find adoption economical and "high investment costs" less of a deterrent. This may be especially true for small size farms. In the meantime, government could consider subsidizing the technology, especially since the economic and environmental benefits could be advanced in justifying the cost.

In this study, the "large farm" characteristic of adopters is consistent with the findings of other studies. The study also found, consistent with other studies, that PA is positively correlated with the educational level of the producer. Unlike other studies, however, adoption is not entirely negatively correlated with the age of the operator. While $43 \%$ of adopters are in the 35 years to 55 -year range, another $36 \%$ are over 55 years of age.

Also, while other studies found irrigated producers more likely to adopt than dryland producers, this study found PA technologies are being applied to more dryland acreage than irrigated acreage. It also found PA technologies are spread across all crop types. The technologies are applied cereals, oilseeds and speciality crops which are critical to the economic vibrancy of the region.

Main motivators for adoption relate to increased yield and improved crop quality. But farmers are also seeking to reduce their work time and workload. Lesser, but still important, reasons relate to reducing inputs of pesticides and herbicides. Reducing water is the least important of the motivators but this may be attributed to the high percentage of PA 
technologies being applied to dryland, not irrigated, crops. In general, environmental reasons are a high motivator for adoption by close to half of the farmers in this study.

Although these results cannot be extrapolated to the entire southern Alberta farming sector, there are several indicators which suggest the region is actively advancing PA technologies and as such, should be experiencing the attendant input, environmental and productivity benefits. Given high satisfaction levels as well as the intentions to continue adoption of PA technologies, farmers are clearly experiencing benefits in adopting PA. As more non-adopters become adopters, the benefits to farmers, the environment and worldwide food production should continue into the future. However, if the small farms remain small and the cost of the technology remains relatively high, there may be limit to the number of farms in this region that adopt PA.

\section{REFERENCES}

[1] Bora, G.C., Nowatzki, J.F. \& Roberts, D.C., Energy savings by adopting precision agriculture in rural USA. Energy Sustainability and Society, 2, p. 22, 2012.

[2] Tey, Y.S. \& Brindal, M., Factors influencing the adoption of precision agriculture technologies: a review for policy implications. Precision Agriculture, 13, pp. 713-730, 2012.

[3] Crookston, K.A., Top 10 List of developments and issues impacting crop management and ecology during the past 50 years. Crop Science, 46, pp. 2253-2262, 2006.

[4] Elferink, M. \& Shierhorn, F., Global Demand for food is rising. Can we meet it? Harvard Business Review, 7 Apr. 2016.

[5] Paarlberg, R., Precision Farming Yields Many Gains, Harvard Kennedy School, Belfer Centre, 2012.

[6] Lambert, D.M., Paudel, K.P. \& Larson, J., Bundled adoption of precision agriculture technologies by cotton producers. Journal of Agricultural and Resource Economics, 40(2), pp. 325-345, 2015.

[7] Cambouris, A.N., Zebarth, B.J., Ziadi, N. \& Perron, I., Precision agriculture in potato production, Potato Research, 57, pp. 249-262, 2014.

[8] Castle, M.H., Lubben, B.D. \& Luck, J.D., Factors Influencing the Adoption of Precision Agriculture Technologies by Nebraska Producers. Working paper, Agricultural Economics Department, University of Nebraska-Lincoln, 2016.

[9] Paxton, K.W. et al., Precision Agriculture technology adoption for cotton production. Proceedings of the Southern Agricultural Economics Association Annual Meeting, 2010.

[10] Daberkow, S.G. \& McBride, W.E., Farm and operator characteristics affecting the awareness and adoption of precision agriculture technologies in the US. Precision Agriculture, 4, pp. 163-177, 2003.

[11] Reichardt, M. \& Jurgens, C., Adoption and future perspective of precision farming in germany: results of several surveys among different agricultural target groups. Precision Agriculture, 10, pp. 73-94, 2009.

[12] Pierpaoli, E., Carli, G., Pignatti, E. \& Canavari, M., Drivers of precision agriculture technologies adoption: a literature review. Procedia Technology, 8, pp. 61-69, 2013.

[13] Aubert, B., Schroeder, A. \& Grimaudo, J., IT as enabler of sustainable farming: an empirical analysis of farmers' adoption decision of precision agriculture technology. Decision Support Systems, 54, pp. 510-520, 2012.

[14] Steele, D., Analysis of Precision Agriculture Adoption And Barriers in Western Canada. Prepared for Agriculture and Agri-food Canada, 2017. 
[15] SouthGrow, Agriculture, Agri-Food \& Bio-Products, Online. http://www.southgrow.com/sites/southgrow.com/files/Key\%20Industry\%20Profile\% 20Agriculture.pdf. Accessed on: 1 Dec. 2017.

[16] Statistics Canada. Census of Agriculture, 2011.

[17] Alberta Agriculture and Forestry (AAF). Irrigation in Alberta, Online. http://www1.agric.gov.ab.ca/\$department/deptdocs.nsf/all/irr7197. Accessed on: 10 Dec. 2017.

[18] Jeffrey, R., The Irrigation Network that Feeds the World. Alberta Venture, Online. $\mathrm{http}$ ://albertaventure.com/water/while-the-rest-of-the-province-was-running-dryfarms-on-southern-alberta-were-thriving/. Accessed on: 15 Dec. 2017.

[19] Alberta Agriculture and Rural Development (AARD). Alberta Irrigation Information: Facts and Figures for the Year 2011. Basin Water Management Branch, Lethbridge, Alberta Canada, 2012.

[20] Paterson Earth \& Water Consulting (PEWC). Economic Value of Irrigation in Alberta. Prepared for the Alberta Irrigation Projects Association. Lethbridge, Alberta. 2015. 